\title{
47. Studies on the Right- and Left-Handedness of Spikelets in Einkorn Wheats. V. Effects of X-Ray Irradiation*)
}

\author{
By Hajime Ono, Noboru Sueoka, Hinako Suemoto, \\ and Ken-ichi KoJIMA \\ (Comm. by H. K.HARA, M.J.A., March 12, 1954)
}

\section{Introduction}

The study on the right- and left-handedness in Einkorn wheat which was started by Kihara (1950), has been undertaken with the aim in view to analyze the involved hereditary and non-hereditary components. In the first report of this series the regularity of the right- and left-handedness of spikelets was expressed as the proportion of concordance (Kihara, Kimura, and Ono, 1951). In two further reports observations on the differentiation of spikelets through the developmental stages have been carried out (Suemoto, 1953), and the nutritional condition was emphasized as one of the environmental factors affecting the proportion of concordance (Kojima, Suemoto, Ono, and Sueoka, 1954). The object of the present study was to analyze the effect of X-ray irradiation as an external agent on right- and left-handedness.

\section{Material and Methods}

Triticum monococcum var. flavescens was used throughout the experiments. The plants were irradiated around the time of double ridge formation in spike primordia (end of March). Ninety $\mathrm{KV}$, $3 \mathrm{~mA}$ and $30 \mathrm{~cm}$ (54 $\mathrm{r}$ per minute) constituted the irradiation conditions and the dosage was regulated by the length of exposure. Except for the experiments of 1950 and 1951, the treated and nontreated materials were planted in pairs in a field so as to eliminate the effect of soil heterogeneity. The design of each experiment will be described in connexion with the respective table. The differences in the mean concordance proportions (Kojima, 1953) between the treated and non-treated plants were statistically compared.

\section{Results of Experiments}

In 1950 , the irradiation of the seedlings was made with various dosages from $3,200 \mathrm{r}$ to $16,000 \mathrm{r}$. The results are shown in Table I.

*) Contributions from the Laboratory of Genetics, Kyoto University, No. 260 . 
Table I

Reduction of mean concordance proportion $\bar{C}$ due to various dosages of X-rays

\begin{tabular}{lcccccc}
\hline Dosage (r) & 0 & 3200 & 6400 & 9600 & 12800 & 16000 \\
\hline Numbers of ears & 52 & 49 & 39 & 57 & 92 & 73 \\
$\vec{C}(\%)$ & 82.65 & 65.20 & 68.06 & 64.47 & 65.37 & 64.51 \\
& \pm 2.48 & \pm 2.83 & \pm 2.92 & \pm 2.05 & \pm 1.98 & \pm 2.06 \\
Reduction of $\bar{C}$ & & 17.49 & $14.59 *$ & 18.18 & 17.28 & 18.14 \\
& & \pm 3.75 & \pm 3.82 & \pm 3.21 & \pm 3.22 & \pm 3.22
\end{tabular}

* Smirnoff-Grubbs' test: $P>0.1$ non-significant

From the results, statistically no difference was found among the mean concordance proportions at various dosages. But, compared with those of the controls, about 17 per cent of reduction were found in the treated plants. Therefore, the effect seems to be the same for doses within the range from $3,200 \mathrm{r}$ to $16,000 \mathrm{r}$.

Further investigations revealed the remarkable fact that the reduction of the mean concordance proportion due to irradiation was partly transmitted to the subsequent generations (Tables II, III).

\section{Table II}

Transmissible effects of X-rays on $\bar{C}(9,600 \mathrm{r})$

\begin{tabular}{|c|c|c|c|}
\hline $\begin{array}{l}\text { Year of irradiation } \\
\text { and further generations }\end{array}$ & X-rayed & Control & Difference \\
\hline $\begin{array}{l}\text { Year of irradiation } \\
(1951)\end{array}$ & $\begin{array}{l}11 \text { plants } \\
110 \text { ears } \\
66.09 \pm 1.48 \%\end{array}$ & $\begin{array}{l}6 \text { plants } \\
77 \text { ears } \\
81.17 \pm 1.21 \%\end{array}$ & $15.08 * * \pm 2.04 \%$ \\
\hline $\begin{array}{l}\text { 1st generation } \\
\qquad(1952)\end{array}$ & $\begin{array}{l}28 \text { plants } \\
280 \text { ears } \\
67.75 \pm 1.20 \%\end{array}$ & $\begin{array}{l}28 \text { plants } \\
280 \text { ears } \\
71.25 \pm 0.96 \%\end{array}$ & $3.50 * \pm 1.48 \%$ \\
\hline $\begin{array}{l}\text { 2nd generation } \\
\qquad(1953)\end{array}$ & $\begin{array}{l}90 \text { plants } \\
450 \text { ears } \\
72.38 \pm 0.58 \%\end{array}$ & $\begin{array}{l}86 \text { plants } \\
430 \text { ears } \\
75.41 \pm 0.66 \%\end{array}$ & $3.04 * * \pm 0.49 \%$ \\
\hline
\end{tabular}

In 1952, the treated and non-treated plants were planted in pairs at corresponding positions in the two rows; in which of the two rows the treated plant should be placed, was determined by chance, and the comparison was made on the pair basis. In 1953, they were also planted in pairs but the comparison was made on the row basis. 
Table III

Transmissible effects of X-rays $(1,600 \mathrm{r})$

\begin{tabular}{clll}
\hline $\begin{array}{c}\text { Year of irradiation and } \\
\text { subsequent generation }\end{array}$ & X-rayed & Control & Difference \\
\hline Year of irradiation & 6 plants & 6 plants & \\
$(1952)$ & 60 ears & 60 ears & \\
& $64.83 \pm 1.47 \%$ & $69.33 \pm 0.85 \%$ & $4.50 * \pm 1.73 \%$ \\
1st generation & 48 plants & 49 plants & \\
$(1953)$ & 240 ears & 245 ears & \\
& $72.06 \pm 0.88 \%$ & $75.40 \pm 0.64 \%$ & $3.34 \pm 1.33 \%$
\end{tabular}

$* 0.01<P<0.05$,

In 1952, the materials were planted in the same way as in 1952 (Table II) and the comparison was made also on the pair basis. In 1953, the materials were divided into 5 blocks, and in each block the treated and non-treated plants were planted in two parallel rows and the comparison was made on the row basis, with the result that the difference between the control and the X-rayed material was not significant.

In 1951 (Table II), although the irradiation was applied to seedlings before the differentiation of spikelets, most of the shoots in all plants were fatally injured, and the mean concordance proportions were obtained from the ears of the shoots which grew later. Therefore, it is quite probable that the investigated shoots had been irradiated in a very early stage of differentiation.

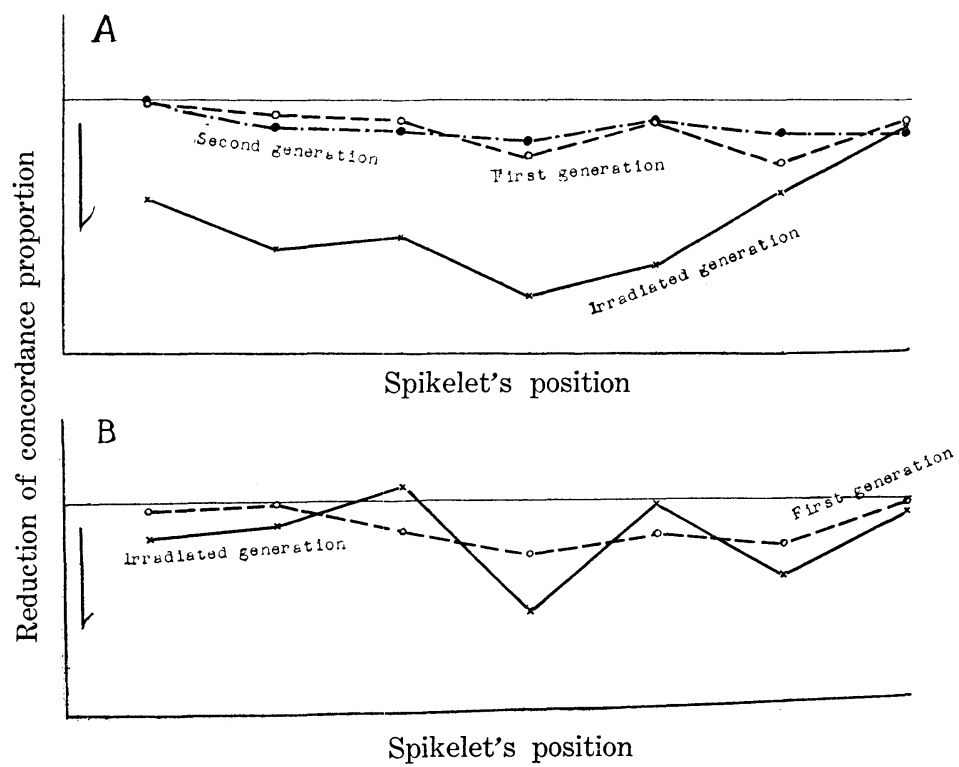

Fig. 1. The reduction of the concordance proportion at each spikelet's position due to X-ray irradiation. A: $9,600 \mathrm{r}$, B: $1,600 \mathrm{r}$ 
According to Table II, as much as 15 per cent of the reduction were observed in the irradiation year. Although this reduction almost disappeared in the first generation after the treatment, about 3 per cent of it were retained and were further carried over to the second generation. The results of another similar experiment with a smaller dosage are given in Table III, which show the same tendency.

These reductions can be further analyzed in relation to the position of spikelets. Fig. 1 shows the reduction of concordance proportion at each spikelet's position compared with the control. Reduction to a larger extent may be found between the 4th and the 18th spikelet.

\section{Discussion}

The constancy of dosage effect within the range from $3,200 \mathrm{r}$ to $16,000 \mathrm{r}$ which was demonstrated in 1950 (Table I), seems to suggest that at $3,200 \mathrm{r}$ the dosage has already reached the maximal effect, so far as the treated generation is concerned. Therefore, a change of the irradiation effect will probably be found in the range below 3,200 r. and the results of Tables II and III actually suggest that this may be the case. This relation will be further investigated in more detail using seeds, since the irradiation conditions cannot accurately be controlled when seedlings are used.

Regarding the transmissible effect of X-ray irradiation (Fig. 2),

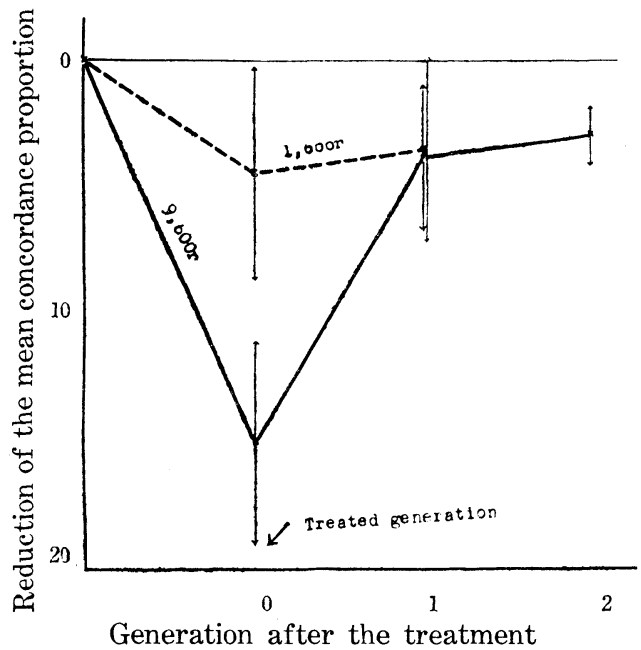

Fig. 2. Recovery of the reduction of the mean concordance proportion due to irradiation in 2 generations after the treatment. The arrows indicate the fiducial interval for 5 per cent level. two alternative mechanisms are possible, namely genic and cytoplasmic changes. In case of a genic change, the marked recovery of the proportion in the first generation after treatment may be due to the drift of the frequencies of mutant genes from one generation to the next, because of the limited number of seeds reserved for the next generation, or to the disappearance of a physiological disturbance caused by the irradiation, leaving only the genic change. The artificial selection of mutant genes must be effec- 
tive, so far as genic change is assumed. On the ground of a cytoplasmic change which seems to be more probable, the heritable effect resembles the phenomenon of "Dauermodifikation" (Jollos, 1939). The validity of these explanations will be tested by reciprocal crossing experiments.

The fact that the reduction of the concordance proportion due to X-ray irradiation appears to be not uniform along the row of spikelets, may offer an important clue for understanding the mechanism of radiation effect. The relationship will be further investigated, by applying irradiation at various stages of development.

\section{Conclusion}

In the present experiments, the disturbing effect of X-ray irradiation as an external agent on right- and left-handedness has been confirmed. Moreover this effect was transmitted to the subsequent generations. The sensitivity to irradiation seems to be greater in the lower than in the upper spikelets. Further study to clarify the mechanism of the radiation effect may throw more light upon the problem of right- and left-handedness which is ultimately a fundamental problem of morphogenesis.

\section{Acknowledgement}

The authors wish to express their hearty gratitude to Prof. H. Kihara for his guidance and encouragement.

\section{References}

Jollos, V.: Grundbegriffe der Vererbungslehre insbesondere Mutation, Dauermodifikation, Modifikation. Handb. d. Vererbungswiss. Bd. 1 D (1939).

Kihara, H.: Right- and left-handedness in plants. "Problems of Modern Biology" edited by K. Nakamura (in. Jap.) (1950).

Kihara, H., Kimura, M., and Ono, H.: Studies on the right- and left-handedness of spikelets in Einkorn wheats. I. Proc. Japan Acad., 27, 678 (1951).

Kojima, K.: Studies on the right- and left-handedness of spikelets in Einkorn wheats. III. Concordance proportion, mean concordance proportion and their relation. Proc. Japan Acad., 29, 576 (1953).

Kojima, K., Suemoto, H., Ono, H., and Sueoka, N.: Studies on the rightand left-handedness of spikelets in Einkorn wheats. IV. Effect of nutritional conditioning. Proc. Japan Acad., 30, 214 (1954).

Suemoto, H.: Studies on the right- and left-handedness of spikelets in Einkorn wheats. II. Developmental process in the ear. Proc. Japan Acad., 29, 362 (1953). 